\title{
KASVATUS\&AIKA
}

KaTSAUS

https://doi.org/10.33350/ka.98305

\section{Kapinalliset koululaiset. Yhteiskunnallisen koululaisliikkeen juurilla}

\begin{abstract}
Essi Jouhki
Lectio praecursoria historian väitöskirjaan Teinikuntatoiminnan sukupolvet. Muistitietohistoria oppikoulujen koululaisliikkeestä 1950-1970-luvuilla, Oulun yliopistossa 21.2.2020.
\end{abstract}

Päättynyt vuosikymmen tullaan muistamaan havahtumisesta ilmastonmuutokseen ja vaatimuksista sen hidastamiseksi. Kenties vielä paremmin tämä ilmastoaktiivisuudeksi nimitetty liikehdintä tullaan muistamaan siitä, että sen etujoukoissa marssivat ennen kaikkea kouluikäiset nuoret ja lapset. Uudenlainen nuorisoaktivismi sai alkunsa vuonna 2018, kun ruotsalainen 14-vuotias Greta Thunberg aloitti yhden naisen ilmastolakkonsa Tukholmassa Ruotsin valtiopäivätalon portailla. Sittemmin kansainväliseksi koululaisliikkeeksi kasvanut ilmastoaktiivisuus on saanut transnationaalisia piirteitä, kun nuoret ympäri maailman ovat osoittaneet huolensa maapallomme tulevaisuudesta ja vaatineet päättäjiä tekemään kestäviä päätöksiä ja ratkaisuja. Esimerkiksi vuoden 2019 aikana ilmastolakoihin osallistui miljoonia koululaisia ja opiskelijoita yli sadasta eri maasta (ks. esim. YLE Uutiset 27.9.2019).

Nuorten yhteiskunnallinen aktiivisuus ei kuitenkaan ole aina ollut yhtä korkeaa, ja olisikin helppoa kuvitella, että ilmiö tulkittaisiin positiivisena asiana. Olemme kuitenkin saaneet lukea uutisotsikoita, joissa koululaisten ilmastoaktivismi saa osakseen kritiikkiä, vähättelyä, irvailua ja jopa suoranaista vihaa. Näissä puheenvuoroissa nuoria kehotetaan muun muassa unohtamaan turhanpäiväinen lakkoilu ja palaamaan takaisin koulunpenkeille. Kritisoivia puheenvuoroja ovat esittäneet niin suurvaltojen johtajat kuin kansalliset ja paikalliset poliittiset päättäjätkin. ${ }^{1}$ Voimakkaat reaktiot kertovat pohjimmiltaan siitä, että lapset ja nuoret ovat ikään kuin astumassa julkiselle politiikan areenalle, jonne he eivät ole ikänsä puolesta vielä toivottuja. Huolestuttavinta kuitenkin on, että äänekkäimpiä ja kriittisimpiä lausuntoja ovat antaneet aikuiset, jotka itse edustavat sukupolvea, joka nuoruudessaan koetteli samoja rajoja, halusi vaikuttaa asioihin ja tehdä maailmasta paremman paikan.

Nykypäivän koululaisten toiminnassa ja vaatimuksissa onkin paljon yhtymäkohtia viiden vuosikymmenen takaiseen, lähes yhtä laajalle levinneeseen nuorisoliikehdintään. Länsimaisessa kulttuuri- ja historiakäsityksessä 1960-luku on vakiintunut vallankumouksen ja

1 Ks. keskustelusta esim. Lehtinen, Iltasanomat 2019; Vaarakallio, YLE Uutiset 2019; O’Connell, The Irish Times 2019; Levsen, Vocal Europe 2019. 
radikalismin vuosikymmenenä, jolloin kansainvälinen nuoriso osoitti mieltään Vietnamin sotaa vastaan sekä kannusti toisiaan kansainväliseen solidaarisuuteen ja rauhanaatteeseen. Niin suomalaisessa kuin kansainvälisessäkin tutkimuksessa "nuoriso" on kuitenkin perinteisesti tarkoittanut poliittisesti, ja usein vasemmistolaisesti, aktivoituneita yliopisto-opiskelijoita.

1960-luvun nuorisoradikalismin historiakuva painottui pitkään vahvasti sukupolven täysi-ikäisten, eliittiin kuuluvien edustajien kokemuksiin. (Hyvärinen 1994; Miettunen 2006; Lalu 2019; Marwick 2006; Vinen 2018.) Vasta 2010-luvulla aiemmin yksiääniseksi jääneen opiskelijaliikkeen historiakuvaa on alettu tulkita moniäänisemmin marginaaliin jääneiden ryhmien, kuten ei-vasemmistolaisten poliittisten ryhmien tai eri-ikäisten nuorten kokemuksien kautta (ks. Hajek 2013). Tutkijat ovat esimerkiksi osoittaneet, miten vastakulttuurien ja uudenlaisen, liberaalin ajatusmaailman nousun myötä myös kouluikäiset nuoret eri puolella länsimaista kulttuuripiiriä alkoivat protestoida konservatiivisia arvoja, normeja ja vaatimuksia vastaan. (Graham 2006; Ides 2014; Cunningham \& Lavalette 2014.) Esimerkiksi Suomessa ja muissa Pohjoismaissa nuorisoliikkeen vaatimukset kohdistuivat muun muassa opiskelijoiden ja koululaisten oikeuksiin, demokraattisiin osallistumismahdollisuuksiin sekä koko koulujärjestelmän murrokseen. (Kärenlampi 1999; Holmén \& Ringarp 2020.) Kuten tänäkin päivänä, nuorison ja aikuisten välinen kuilu tuntui syvemmältä kuin koskaan.

Tänään tarkastettava väitöstutkimus tarkentaa käsitystämme koululaisaktivismin historiasta ja osoittaa, että kyse on transnationaalista ilmiöstä, jota on tulkittu ja käsitelty eri tavoin eri aikoina. Tutkimuksen kohteena ovat Suomessa 1950-1970-luvuilla oppikoulua käyneet nuoret ja heidän kokemuksensa ja muistonsa ajan koululaisliikkeestä. Tuolloin globalisaatio tai maailman avautuminen olivat vasta aluillaan, mutta siitä huolimatta koululaisia huolestuttivat tapahtumat niin kotimaassa kuin maailmallakin: epävarmuus, kriisit, sodat, ihmisoikeuksien sortaminen ja maailman epäoikeudenmukaisuus. Samaan aikaan nuoret etsivät mahdollisuuksia vaikuttaa ja osallistua yhteiskunnalliseen keskusteluun, jonne he eivät olleet aiemmin olleet tervetulleita.

Toisin kuin nykypäivän sosiaalisen median ja teknologiayhteiskunnan aikana, nuorison äänen kuuleminen ei ollut itsestäänselvyys. Aina 1960-luvun lopulle asti suomalaisia lapsia ja nuoria kasvatettiin kuuliaisuuteen porvarillisen oppikouluideologian pohjalta. Hallitsevaan kasvatusihanteeseen eivät kuuluneet auktoriteettien kyseenalaistaminen tai omien, varsinkaan poliittisten mielipiteiden ilmaiseminen. (Kaarninen 2011; Koski 2003.) Valppaan ja aikaansa seuraavan koululaisnuorison toiminta- ja vaikutuskanava löytyikin yllättäen vanhasta koululaisperinteestä, oppikouluissa toimineista teinikunnista.

Nykypäivän oppilaskuntiin rinnastettavat teinikunnat olivat oppikoulujen lukioluokkalaisten omaehtoinen toimintamuoto, joka tarjosi nuorille mahdollisuuden suunnitella, toimia ja toteuttaa yhdessä heille tärkeitä asioita. Teini oli arvostettu titteli, joka - toisin kuin nykypäivänä - tarkoitti aktiivista noin 15-19-vuotiasta lukiolaisnuorta. Paikallisten teinikuntien kattojärjestönä toimi jo vuonna 1939 perustettu Suomen Teiniliitto², joka toimi aluksi vain löyhänä yhteistyöelimenä, kunnes 1950-luvun lopulta alkaen sen vaikutusvalta alkoi kasvaa ja siitä muodostui oppikoululaisten edunvalvoja ja virallinen äänitorvi. 1960luvun lopulla liki 70 prosenttia lukiolaisista oli Teiniliiton jäsenenä. Järjestön suosion taus-

2 Järjestö perustettiin alun perin Suomen Oppikoulujen Toverikuntien Liitoksi, mutta jo vuonna 1943 sen nimi vaihdettiin Suomen Teiniliitoksi. 
talla vaikutti pitkälti se, että toiminta oli lähes täysin aikuisten ohjauksen ulkopuolella: Teiniliiton hallitukseen valittiin vain ylioppilaita, jotka olivat entisiä teiniaktiiveja. Teiniliitto oli siis pohjimmiltaan nuorisojärjestö, jonka johdossa olivat nuoret itse.

Paikalliset teinikunnat oli alun perin tarkoitettu koulujen sisällä toimivaksi oppilaiden vapaamuotoiseksi harrastuskanavaksi. Esimerkiksi toisen maailmansodan jälkeisinä vuosina toiminnan keskiössä olivat monipuoliset kerhot, erilaiset kulttuuriaktiviteetit ja koululaisjuhlat. Viattomuuden ajaksikin nimitetty 1950-luku oli etuoikeutetun teininuorison näkökulmasta hauskaa ja kilttiä aikaa, jota sävyttivät yhtä aikaa niin teinitanssit kuin kristilliset teinitilaisuudetkin (ks. Korkiakangas 2013, 19). Koko toimintaa ohjasi vielä juhlallinen Teinijulistus ja sen neljä pääkohtaa: Jumala, Isänmaa, Työ ja Velvollisuus.

Teinitoiminnan isänmaallis-puolustuksellinen paatos jäi kuitenkin nopeasti taka-alalle, kun jälleenrakennusajan Suomi alkoi nousta hitaasti jaloilleen. 1950-luvun lopun merkittävät murrokset, kuten suomalaisten kiristynyt suhde Neuvostoliittoon tai kulttuuripiireistä levinnyt yhteiskuntakritiikki, eivät jääneet teineiltä huomaamatta. (Kolbe 1996.) Tutkimukseen osallistunut oululainen Annikki kuvaili osuvasti nuorten yhteiskunnallista innostumista "50-luvun nälkänä", jolla hän viittasi siihen, miten aiemmin politiikka ja sen perinteiset teemat oli nähty vain aikuisten keskustelunaiheina. 1950-luvun lopulla myös koululaisnuoriso halusi ottaa osaa keskusteluun ja tuulettaa sitä uudelle vuosikymmenelle. Teininuoriso ikään kuin havahtui siihen, että yhteiskunta oli olemassa ja sitä pystyi ja täytyi käsitellä jotenkin. Teinikunnista muodostui otollinen alusta ja kanava kertoa ympäröivälle yhteisölle, että "olemme vakavissamme ja meillä on asiaa".

Esimerkiksi Suomen Kuvalehdessä huomioitiin keväällä 1967 teinitoiminnassa tapahtunut murros. Lehdessä kirjoitettiin uudenlaisesta teinityypistä seuraavasti:

Näin murtautui 60-luvun puolivälissä esiin aivan uusi teinityyppi, 15-19-vuotias nuori ihminen, jolla on beatles-tukka tai minihame, mutta pää täynnä mielipiteitä ja ajatuksia. Passiivinen viihteellisyys on nyt taakse jäänyttä elämää. Nykyaikainen teini esittää myös kysymyksiä yhteiskunnalle, kirkolle, koululle, vanhemmille. Enää ei keskitytä vain oman koulun piiriin. Nuoriso on alkanut ajaa omaa asiaansa. (Suomen Kuvalehti 14.1.1967.)

1960-luvun teinien koululaisliike voidaan nähdä eräänlaisena vastauksena nuorten kasvatusta ja poliittista osallistumista koskevaan ristiriitaan: yhtäältä oppikoululaisista haluttiin kasvattaa vastuullisia yhteiskunnallisia toimijoita, mutta toisaalta poliittinen toiminta katsottiin osaksi aikuismaailmaa, eikä näin lainkaan sopivaksi nuorille tai kouluikäisille lapsille (vrt. Koski 2003; Tuominen 1991). 1960-luvun kuluessa valppaat nuoret puolustivat oikeuttaan osallistua yhteiskuntaan ja vaativat ajantasaista opetusta yhteiskunnallisiin taitoihin.

Samoihin aikoihin "koululaisten ammattiliitoksi" tituleerattu Teiniliitto alkoi ajaa koululaisten etuja entistä aggressiivisemmin. Kouludemokratia oli koululaisliikkeen keskeisin ja tärkein päämäärä, jonka puolesta oltiin valmiita taistelemaan. Vuosikymmenen lopulla oppikoululaiset nousivat yhtenä rintamana vaatimaan oppilaiden demokraattisia oikeuksia sekä oppikoulujen ja opetuksen totaalista uudistamista. Samaan aikaan suomalaiset koululaiset jakoivat kansainvälisen opiskelijaliikkeen tavoin huolen kolmannen maailman ongelmista, Vietnamin sodasta ja imperialismin vaikutuksista. (Kärenlampi 1999.)

Teinien valpastuminen ei kuitenkaan aina saanut positiivista vastaanottoa, vaan se aiheutti pelkoa ja huolta aikuisten ja kasvattajien taholta. 1970-luvulla kasvattajat ja vanhemmat seurasivat kauhuissaan, kun Teiniliiton johtamat koululaiset tempautuivat nuoruu- 
den vimmalla ja innolla puoluepolitiikkaan, jonka tempoiluilta eivät säästyneet niin yhteis kunta- kuin koulurauhakaan. (Kärenlampi 1999; Okkonen 2017.) 1960-luvun lopulla puolueiden nuoriso-osastoissa kävi kuhina, sillä liki 90000 nuorta oli tulossa äänestysikään. Kaikki tämä heijastui Teiniliittoon ja koululaisliikkeeseen, joiden sisälle perustettiin pysyviä, puoluesidonnaisia rintamalinjoja. Suurta osaa koululaisnuorisosta viehätti perinteinen, porvarillinen ajatusmaailma, mutta yhä useampi nuori etsi poliittista kotiansa enemmän vasemmalta ja sen äärilaidoilta. (Rentola 2012.)

Ideologisista kiistoista ja riidoista huolimatta koululaisliikettä ajoi yksi yhteinen päämäärä: kouluneuvostot. Kouludemokratian ihanteena oli, että oppilaat pääsisivät vaikuttamaan koulujen sisäisiin asioihin vaalein valittujen kouluneuvostojen kautta. Todellisuus oli lopulta kaikkea muuta: suurin odotuksin valitut oppilaat päätyivät päättämään lähinnä jälkiistunnoista ja järjestyssäännöistä. Kouludemokratian toteutumisessa oli kuitenkin pohjimmiltaan kyse siitä, että koululaiset itse onnistuivat vaikuttamaan koko koulujärjestelmän rakenteisiin ja murtamaan opettajien auktoriteettiasemaa.

1950-1970-lukujen koululaisaktivismista on perusteltua puhua sukupolviliikkeenä, jonka keskeinen yhdistävä tekijä oli teinikuntalaisuus. Koko teinikuntatoiminnan traditio ulottui liki neljän vuosikymmenen yli, ja kukin oppikoululaispolvi vuorollaan koki sen omakseen ja muokkasi siitä oman näköisensä. 15-19-vuotiaat teinit olivat lähtökohtaisesti otollisessa herkkyysiässä, jolloin sosiologisen ja mannheimilaisen sukupolvitutkimuksen mukaan yhteiskunnalliset ja yhteisölliset murrokset koetaan voimakkaimmin. Juuri tässä iässä koetut ja jaetut kokemukset määrittelevät sukupolvikokemuksen. (Virtanen 2002, 23.) Kuten sosiologi Semi Purhonen (2005, 254-258)on määritellyt, sukupolviliikkeen kriteereinä ovat jäsenten samanikäisyys, jokin jaettu yhteinen, aktivoiva kokemus sekä tunne kuulumisesta sukupolveen.

Teiniliitto oli avainasemassa sukupolvikokemuksen ylläpitämisessä. Se toimi yhdistävänä linkkinä kaikille teineille eri puolella Suomea. Sen piirissä syntyneet verkostot mahdollistivat sen, että jopa Pohjois-Suomen syrjäseuduilla koulua käyvät nuoret olivat tietoisia koululaisliikkeen vaatimuksista ja tapahtumista. Näin laajamittainen koululaisten järjestäytyminen yhteisten päämäärien taakse on ollut poikkeuksellista sekä kansainvälisen että suomalaisen nuorison historiassa. Koululaisaktivismi itsessään ei ole ollut vieras ilmiö muuallakaan maailmassa, mutta harvemmin nuoret ovat itse perustaneet yhtä organisoituneita ja aikuisista riippumattomia järjestöjä. (Vrt. Graham 2005; Cunningham \& Lavalette 2014.)

Teiniliitto ja koko oppikouluajan koululaisliike kohtasivat kuitenkin loppunsa vuonna 1975: Teiniliitto ajautui konkurssiin epäselvissä olosuhteissa, ja samaan aikaan PohjoisSuomesta vaiheittain alkanut peruskoulu-uudistus muutti suomalaista koulua perusteellisesti. Koululaispolitiikan ylikuumenemisen jälkeen politiikka sai näennäisen porttikiellon kouluihin. Oppikoulujen ajan ja Teiniliiton huippuvuosien jälkeen ei ole enää noussut yhtä aktiivista ja vaikutusvaltaista koululaisjärjestöä. Toisaalta voidaan pohtia, onko muuttuvassa maailmassa enää edes ollut tarvetta sellaiselle. Esimerkiksi nykypäivän nuorisoliikkeet ovat aktivoituneet pääasiassa vapaamuotoisesti sosiaalisessa mediassa ja ilman vahvaa keskusohjausta. 1950-70-luvuilla nuorison äänen kuulemiseksi tarvittiin kuitenkin vielä vaikutusvaltaista kattojärjestöä.

Historiallisesti katsottuna nuorison kapina ja aktivismi ovat enemmän sääntö kuin poikkeus. Nuorisoryhmät ovat aina pyrkineet löytämään paikkansa yhteiskunnassa ja liittyneet yhteen ajamaan heille tärkeitä asioita. Keinot vain ovat vaihdelleet. Esimerkiksi 2000luvun alussa kansainväliset ja kansalliset tutkimukset osoittivat huolestuttavia merkkejä siitä, että suomalaisten nuorten yhteiskunnallinen aktiivisuus ja kiinnostus olivat laskussa. (Suoninen et al. (toim.) 2010.) Jo tuolloin nuorisotutkijat Tommi Hoikkala, Sofia Laine ja 
Jyrki Laine halusivat osallistua ajankohtaiseen keskusteluun ja osoittaa toimittamallaan Mitä on tehtävä? Nuorison kapinan teoriaa ja käytäntöä -teoksella (2005), että nuorten yhteiskunnallinen aktiivisuus ei tosiasiassa ollut kadonnut minnekään. Sen sijaan nuorison toiminta oli muuttanut vuosikymmenten aikana muotoaan ja kanavoitunut perinteisten osallistumiskanavien, kuten puolueiden, ulkopuolelle. Esimerkiksi Helena Helve $(2005,208)$ kirjoitti, miten 2000-luvun alussa globalisaatiokriittiset nuorisoaktivistit vaikuttivat olleen kiinnostuneita epätavanomaisista, kansalliset rajat ylittävistä ja henkilökohtaisista vaikutuskeinoista, kuten eettisistä kulutusvalinnoista, protestitoiminnasta tai jopa anarkismista.

Tämä väitöstutkimus osoittaa, että nuorisoliikkeiden historia on luonteeltaan aaltoliikettä. Viimeisen sadan vuoden aikana olemme nähneet nuorten aktivoituvan niin fennomanian, heimoaatteen, fasismin, kulttuuriradikalismin, rauhanaatteen, taistolaisuuden, feminismin, ympäristöliikkeen kuin globalisaatiovastaisuudenkin hengessä. Myös nuorten vaikuttamis- ja osallistumismekanismeissa on nähtävissä aaltomaista liikettä: kun 70-luvun koululaisaktivisti nojasi puoluepohjaiseen joukkovoimaan, 2000-luvun alun nuori korosti henkilökohtaisten valintojen ja tekojen merkitystä. Nykypäivän ilmastolakkoliike on puolestaan osoittanut, että joukkovoima on jälleen käyttökelpoinen väline. Tämä näkyy myös tuoreimmissa nuorisotutkimuksissa, joiden mukaan nuorten yhteiskunnallinen aktiivisuus ja kiinnostus politiikkaan on noussut ennätystasolle sitten 1990-luvun alun (Pekkarinen \& Myllyniemi (toim.) 2019).

Koululaisliikkeen historian tutkimus osoittaa myös sen, että nuorten ihmisten on mahdollista muuttaa yhteiskuntaa ja maailmaa. Se on osoitus siitä, että jos nuorissa ihmisissä on tahtoa ja voimaa, he voivat saada aikaiseksi mitä vain. Käsillä oleva väitöstutkimus muistuttaa nykypäivän aikuisia siitä, että mekin olimme kerran nuoria, joilla oli tavoitteita, toiveita, jopa utopistisia päämääriä. Olkoon tämä lohdullisina sanoina myös nykypäivän "ilmastosukupolvelle", jotta se voisi katsoa toiveikkaammin tulevaan.

\section{Väitöskirja}

Jouhki, Essi 2020. Teinikuntatoiminnan sukupolvet. Muistitietohistoria oppikoulujen koululaisliikkeestä 1950-1970-luvuilla. Acta Universitatis Ouluensis. B Humaniora 178. Oulun yliopisto [www-lähde]. $<$ http://urn.fi/urn:isbn:9789526225173 $>$.

\section{Sanomalehdet}

Lehtinen, Lasse 2019. Ilmastosodan söpö soturi. Iltasanomat 25.8.2019 [www-lähde]. < https://www.is.fi/ulkomaat/art-2000006213598.html > (Luettu 20.2.2020).

O'Connell, Jennifer 2019. Why is Greta Thunberg so triggering for certain men? The Irish Times 7.9.2019 [www-lähde]. < https://www.irishtimes.com/life-and-style/people/whyis-greta-thunberg-so-triggering-for-certain-men-1.4002264? $\operatorname{mode}=\mathrm{amp}>$ (Luettu 20.2.2020).

Levsen, Stephanie 2019. Critics of The Climate School Strikes: Who's The Child And Who's The Adult? Vocal Europe 20.3.2019 [www-lähde]. < https://www.vocaleurope.eu/critics-of-the-climate-school-strikes-whos-the-child-and-whos-the-adult/ (Luettu 20.2.2020). 
Vaarakallio, Sampo 2019. Pahvilaatikon päältä parrasvaloihin - Miksi Greta Thunberg vetää puoleensa setäraivoa. YLE Uutiset 26.9.2019 [www-lähde]. < $\underline{\text { https://yle.fi/uutiset/ }}$ $\underline{\text { 3-10988700 }}>$ (Luettu 20.2.2020).

\section{Kirjallisuus}

Cunningham, Steve \& Lavalette, Michael 2014. Schools Out! The Hidden History of Britain's School Student Strikes. London: Bookmarks.

Graham, Gael 2005. Young Activists: American High School Students in the Age of Protest. DeKalb: Northern Illinois University Press.

Hajek, Andrea 2013. Challenging Dominant Discourses of the Past: 1968 and the Value of Oral History. Memory Studies 6 (1), 3-6. $\underline{\text { https://doi.org/ }}$ $10.1177 \% 2 \mathrm{~F} 1750698012463887$

Helve, Helena 2005. Nuorten arvojen, maailmankuvien ja katsomusten muutokset. Teoksessa Hoikkala, Tommi, Laine, Sofia \& Laine, Jyrki (toim.), Mitä on tehtävä? Nuorison kapinan teoriaa ja käytäntöä. Helsinki: Nuorisotutkimusverkosto/Nuorisotutkimusseura, 205-224.

Hoikkala, Tommi, Laine, Sofia \& Laine, Jyrki (toim.) 2005. Mitä on tehtävä? Nuorison kapinan teoriaa ja käytäntöä. Helsinki: Nuorisotutkimusverkosto/Nuorisotutkimusseura.

Holmén, Janne \& Ringarp, Johanna 2020. 1968 och reformer av högre utbildning i Finland och Sverige. Teoksessa Burman, Anders \& Landahl, Joakim (toim.), 1968 och pedagogiken. Södertörn Studies in Intellectual and Cultural History 4. Stockholm: Södertörn University, 49-70.

Hyvärinen, Matti 1994. Viimeiset taistot. Tampere: Vastapaino.

Ides, Matthew 2014. "Dare to Free Yourself": The Red Tide, Feminism, and High School Activism in the Early 1970s. Journal of History of Childhood and Youth 2 (7), 295-319. https://doi.org/10.1353/hcy.2014.0031

Kaarninen, Mervi 2011. Oppikoulu yhteiskunnan rakentajana. Teoksessa Heikkinen, Anja \& Leino-Kaukiainen, Pirjo (toim.), Valistus ja koulunpenkki: Kasvatus ja koulutus Suomessa 1860-luvulta 1960-luvulle. Helsinki: SKS, 405-429.

Kolbe, Laura 1996. Eliitti, traditio, murros: Helsingin yliopiston ylioppilaskunta 19601990. Helsinki: Otava.

Korkiakangas, Pirjo 2013. Onnen aika lapsuuden. Teoksessa Hytönen, Kirsi-Maria \& Rantanen, Keijo (toim.), Onnen aika? Valoja ja varjoja 1950-luvulta. Jyväskylä: Atena, 19-30.

Koski, Leena 2003. Oppikoulunuoruus 1940-1950-luvuilla. Teoksessa Aapola, Sinikka \& Kaarninen, Mervi (toim.), Nuoruuden vuosisata: Suomalaisen nuorison historia. Helsinki: SKS, 283-314.

Kärenlampi, Paavo 1999. Taistelu kouludemokratiasta: Kouludemokratian aalto Suomessa. Helsinki: Suomen historiallinen seura.

Lalu, Liisa 2019. "Kädet irti Vietnamista!" Vietnamin puolesta taisteleva nuoriso. Teoksessa Koivisto, Hanne, Kärki, Kimi \& Leskelä-Kärki, Maarit (toim.), Ilmestyskirja. Vietnamin sodan kulttuurihistoriaa. Vantaa: Työväen historian ja perinteen tutkimuksen seura, 307-336.

Marwick, Arthur 2006. Youth Culture and the Cultural Revolution of the Long Sixties. Teoksessa Schildt, Axel \& Detlef Siegfried (toim.), Between Marx and Coca-cola. 
Youth Cultures in Changing European Socities, 1960-1980, New York; Oxford; Berghahn Books, 39-58.

Miettunen, Katja-Maria 2009. Menneisyys ja historiakuva: Suomalainen kuusikymmentäluku muistelijoiden rakentamana ajanjaksona. Helsinki: SKS.

Okkonen, Ville 2017. Peruskoulua vastaan: Yksityiskoulut ja yhteiskuntajärjestys 19661975. Turku: Turun yliopisto.

Pekkarinen, Elina \& Myllyniemi, Sami (toim.) 2019. Vaikutusvaltaa Euroopan laidalla. Nuorisobarometri 2019. Tampere: Nuorisotutkimusverkosto/Nuorisotutkimusseura.

Purhonen, Semi 2005. Onko Attac sukupolviliike? Ja mikä sukupolviliike oikein on? Teoksessa Hoikkala, Tommi, Laine, Sofia \& Laine, Jyrki (toim.), Mitä on tehtävä? Nuorison kapinan teoriaa ja käytäntö̈̈. Helsinki: Nuorisotutkimusverkosto/Nuorisotutkimusseura, 239- 288.

Rentola, Kimmo (2012) Suomen Teiniliiton nousu ja tuho. Teoksessa Pauli Kettunen \& Hannu Simola (toim.), Tiedon ja osaamisen Suomi. Kasvatus ja koulutus Suomessa 1960-luvulta 2000-luvulle. Helsinki: SKS, 175-181.

Suoninen, Annika, Kupari, Pekka \& Törmäkangas, Kari (toim.) 2010. Nuorten yhteiskunnalliset tiedot, osallistuminen ja asenteet: kansainvälisen ICCS 2009 -tutkimuksen päätulokset. Koulutuksen tutkimuslaitos. Jyväskylän yliopisto [www-lähde]. < https:// jyx.jyu.fi/bitstream/handle/123456789/37474/978-951-39-4107-9.pdf? sequence $=1 \&$ is Allowed $=\mathrm{y}>($ Luettu 12.8.2018).

Tuominen, Marja (1991). "Me kaikki ollaan sotilaitten lapsia": Sukupolvihegemonian kriisi 1960-luvun suomalaisessa kulttuurissa. Helsinki: Otava.

Vinen, Richard (2018). The Long '68: Radical Protest and Its Enemies. Lontoo: Allen Lane.

Virtanen, Matti 2002. Fennomanian perilliset. Poliittiset traditiot ja sukupolvien dynamiikka. Helsinki: SKS.

FT Essi Jouhki työskentelee Jyväskylän yliopiston Historian ja etnologian laitoksella post doc -tutkijana. 